\title{
Cesarean delivery rates, hospital readiness and quality of clinical management in Ethiopia: national results from two cross- sectional emergency obstetric and newborn care assessments
}

Misrak Getnet Beyene ${ }^{1 *} \mathbb{D}$, Theodros Getachew Zemedu', Azmach Hadush Gebregiorgis ${ }^{2}$, Ana Lorena Ruano ${ }^{3}$ and Patricia E. Bailey ${ }^{4}$

\begin{abstract}
Background: Cesarean delivery (CD) rates have reached epidemic levels in many high and middle income countries while increasingly, low income countries are challenged both by high urban CD rates and high unmet need in rural areas. The managing authority of health care institutions often plays a role in these disparities. This paper shows changes between 2008 and 2016 in Ethiopian CD rates, readiness of hospitals to provide CD and quality of clinical care, while highlighting the role of hospital management authority.
\end{abstract}

Methods: This secondary data analysis draws from two national cross-sectional studies to assess emergency obstetric and newborn care. The sample includes 111 hospitals in 2008 and 316 hospitals in 2016, and 275 women whose CD chart was reviewed in 2008 and 568 in 2016. Descriptive statistics are used to describe our primary outcome measures: population- and institutional-based CD rates; hospital readiness to perform CD; quality of clinical management, including the relative size of Robson classification groups.

Results: The national population CD rate increased from 2008 to $2016(<1$ to 2.7\%) as did all regional rates. Rates in 2016 ranged from $24 \%$ in urban settings to less than 1\% in several rural regions. The institutional rate was $54 \%$ in private for-profit hospitals in 2016, up from $46 \%$ in 2008. Hospital readiness to perform CDs increased in public and private for-profit hospitals. Only half of the women whose charts were reviewed received uterotonics after delivery of the baby, but use of prophylactic antibiotics was high. Partograph use increased from 9 to $42 \%$ in public hospitals, but was negligible or declined elsewhere. In 2016, 40\% of chart reviews from public hospitals were among low-risk nulliparous women (Robson groups 1\&2).

\footnotetext{
* Correspondence: misrakg81@gmail.com

${ }^{1}$ Ethiopian Public Health Institute, Addis Ababa, Ethiopia

Full list of author information is available at the end of the article
}

(c) The Author(s). 2021 Open Access This article is licensed under a Creative Commons Attribution 4.0 International License, which permits use, sharing, adaptation, distribution and reproduction in any medium or format, as long as you give appropriate credit to the original author(s) and the source, provide a link to the Creative Commons licence, and indicate if changes were made. The images or other third party material in this article are included in the article's Creative Commons licence, unless indicated otherwise in a credit line to the material. If material is not included in the article's Creative Commons licence and your intended use is not permitted by statutory regulation or exceeds the permitted use, you will need to obtain permission directly from the copyright holder. To view a copy of this licence, visit http://creativecommons.org/licenses/by/4.0/. The Creative Commons Public Domain Dedication waiver (http://creativecommons.org/publicdomain/zero/1.0/) applies to the data made available in this article, unless otherwise stated in a credit line to the data. 
Conclusions: Between 2008 and 2016, government increased the availability of CD services, improved public hospital readiness and some aspects of clinical quality. Strategies tailored to further reduce the high unmet need for CD and what appears to be an increasing number of unnecessary cesareans are discussed. Adherence to best practices and universal coverage of water and electricity will improve the quality of hospital services while the use of the Robson classification system may serve as a useful quality improvement tool.

Keywords: Cesarean delivery, Cesarean-section, Cesarean rates, Readiness, Robson classification, Public/private managing authority, Quality of care

\section{Background}

Increasingly, low and middle income countries face the two extremes of unmet need for and unnecessary cesareans, or "too little too late and too much too soon" [1]. The World Health Organization (WHO) began producing global guidance on this topic as early as 1985 [2]. In 2015, the WHO provided evidence that rates greater than $10 \%$ were not associated with a reduction in maternal and newborn mortality. At the same time, the WHO cautioned against pursuing specific targets and stressed that all women who need a CD should receive one $[3,4]$. Women who have a cesarean undergo perioperative risks such as blood loss, anesthetic accidents, wound infection and iatrogenic fistula, and put future pregnancies at risk due to uterine scaring [5-7]. But where cesarean deliveries are too few, we see excessive short- and longterm maternal morbidity and maternal and newborn mortality that could be mitigated by timely surgical intervention.

Eastern and southern Africa has marginally increased its CD rate from 4.6 to $6.2 \%$ between 2000 and 2015 compared to most of Asia and Eastern Europe where rates more than doubled during this period, and in 2015, ranged from 18 to $29 \%$ [8]. Recent global interest and regional studies on surgery have highlighted extensive unmet need for surgery. They also documented safety concerns when undertaken too late or in environments where deficits in surgical personnel and resources are common, such as oxygen, medical equipment and electricity $[9,10]$.

Ethiopia is a country with high maternal and newborn mortality, high prevalence of fistula and historically low cesarean and institutional delivery rates. According to its 2016 Demographic and Health Survey, the CD rate was $2 \%$ based on births during the 5 years prior to the survey [11]. Earlier trend data from the capital indicated rising cesarean rates that were positively correlated with income and education, as in many other country settings $[8,12,13]$. The current Health Sector Transformation Plan set a population-based cesarean target of $8 \%$ for 2020 as a step towards addressing the unmet need for life-saving surgery [14].

This paper aims to update an earlier paper written by Fesseha and colleagues that described a national review of cesarean delivery in Ethiopia in 2008 [15]. The current paper compares 2008 with the situation in 2016 and describes changes in national and regional population $\mathrm{CD}$ rates; institutional $\mathrm{CD}$ rates; the readiness of hospitals to perform obstetric surgery; and the quality of clinical management of cesarean delivery, while highlighting differences across hospital management.

\section{Methods}

\section{Study design, setting and data collection}

This secondary data analysis draws on two national cross-sectional surveys or assessments of emergency obstetric and newborn care (EmONC) from 2008 and 2016 $[16,17]$. Each was a census of public and private health facilities that met government criteria to provide childbirth services.

The data collection instruments for 2008 were adapted from a set of standard modules previously used in many countries [18]. The 2016 assessment used the same core questionnaires administered in 2008 that subsequently underwent a global revision with local adaptation in 2016. The six modules relevant to this study were: M1 basic health facility infrastructure; M2 - human resources; M3 - inventory of drugs, equipment and supplies; M4 - summary service statistics; M5 - performance of signal functions; and M8 - chart review for CDs. All facilities received modules $1-5$; only facilities that performed CDs received M8. The latter was modified in 2016 to include information not in 2008 such as a woman's characteristics needed to classify her into one of the 10 Robson groups, as well as type of anesthesia and professional cadre who performed the operation. See supplementary files $1,2,3,4,5$ and 6 for the modules.

The first assessment was launched 1 October 2008 and completed by 15 January 2009; the 2016 assessment commenced in mid-May and was completed by midDecember 2016. In 2008, a private company conducted the assessment and prepared the databases [16] and in 2016, this responsibility shifted to the Ethiopian Public Health Institute. Details about the data collector training and survey execution can be found in the final reports and previously published papers $[15-17,19]$. 


\section{Study population}

This paper features three study populations or units of analysis: 1) aggregated hospital service data, 2) hospitals and 3 ) individual women who delivered by cesarean.

Aggregated service data consisted of the number of women who delivered in each facility by mode of delivery and covered 12 consecutive months prior to the assessment (July 2007-June 2008 and January-December 2015). These data were used to estimate population and institutional $\mathrm{CD}$ rates. The 12-month tally of the number of women who received a cesarean delivery in 2008 was 17,145 and the total number who delivered in these same facilities during the same time period were 93,689. In 2016 those numbers increased to 78,916 cesarean deliveries among 343,492 institutional deliveries.

The second study population was the health facility. If the Ethiopian Food, Medicine and Health Control Authority approved a facility as a site to deliver routine and/or operative childbirth services, it was eligible for the assessment. Between 2008 and 2016 the Ministry of Health led a massive infrastructure expansion, adding about 3000 health centers and 200 hospitals [20, 21]. In 2008, 751 health facilities with childbirth services were visited, including 111 hospitals. In 2016, 3804 health facilities were visited, 316 of which were hospitals. This paper focuses exclusively on the hospitals.

Although we call both assessments a census, in 2008, 15 facilities were not visited because they did not appear on the master list of licensed facilities, 12 of which were in the capital of Addis Ababa. In 2016, 11 facilities were not visited due to civil unrest but few if any of these service sites were hospitals. Finally, two hospitals refused to participate in the 2016 assessment. Nevertheless, we consider our estimates to be based on national "populations" of health facilities and of women who gave birth in facilities rather than samples.

The third study population was defined by the women whose cesarean delivery was selected for review. In each hospital that had performed cesarean delivery, a small sample of women who delivered by cesarean had their charts reviewed. In 2008 data collectors identified three women per hospital and in 2016 only two cases per hospital were selected; the number was reduced due to the increase in the number of hospitals and the time required to complete chart reviews. The selection criteria were the same for each assessment: 1) cases occurred in the previous 12 months, and 2) they were the last women who had had a cesarean but were no longer under postoperative care, regardless of survival. Although the cases were systematically chosen, technically they were a convenience sample. In 2008, 275 women who underwent $C D$ were reviewed and in 2016 that number was 568.

\section{Processes and comparisons}

\section{Variables, readiness definition and Robson classification}

Our key stratifying variable across all analyses was hospital managing authority, defined by three categories of hospitals: public or government hospitals, private forprofit hospitals and private not-for-profit hospitals (managed by non-governmental organizations and/or religious missions).

For both population and institutional $C D$ rates, the numerator was the sum of all CDs performed at each hospital. The denominator for the population rate was the number of expected births in each region, based on population figures from the Planning and Programming Department of the Federal Ministry of Health $[20,22]$. The population figures were multiplied by the crude birth rate established by the 2016 Demographic and Health Survey and FMoH reports in 2008 [11, 22]. The use of expected births rather than known births is standard methodology for EmONC assessments since vital registration of all births is often incomplete [23]. The denominator for the institutional $C D$ rate was the sum of all births at each hospital that reported having provided cesarean services in module 4.

Modules 1, 2, 3 and 5 provided information to assess hospital readiness to perform $\mathrm{CD}$. To assess readiness, we created a binary summary score (yes or no), based on 1) the availability of at least one health professional able to perform the operation and another individual to provide anesthesia, plus 2) functional readiness items. The latter included EITHER an anesthesia machine + (halothane or ketamine) OR regional anesthesia (lignocaine/ lidocaine $4 \%$ or bupivacaine) AND an oxygen cylinder with manometer and flowmeter (low flow) tubes and connectors, an operating table and a functioning adjustable light. Although not included in the summary score of readiness requirements, interruptions in water and electricity in the operation theaters were assessed also.

Information on the quality of clinical management was drawn from module 8 and was measured by the use of a partograph, administration of prophylactic antibiotics and uterotonics, time interval from decision to incision, type of anesthesia and the clinician who performed the $\mathrm{CD}$ as well as maternal and newborn outcomes.

A final analysis of clinical management was based on the Robson 10-group classification scheme, designed to determine institutional cesarean rates for clinically relevant and mutually exclusive groups [24]. The classification system depends on six characteristics of women that are easily captured: parity (nulliparous/multiparous), number of fetuses (singleton/multiple), onset of labor (spontaneous or induced/CD before labor started), previous CD (yes/no), fetal lie (cephalic/ transverse/breech) and gestational age $(<37$ weeks/ $\geq 37)$. Because the 10 groups (see Fig. 1) tend to have different cesarean rates, 


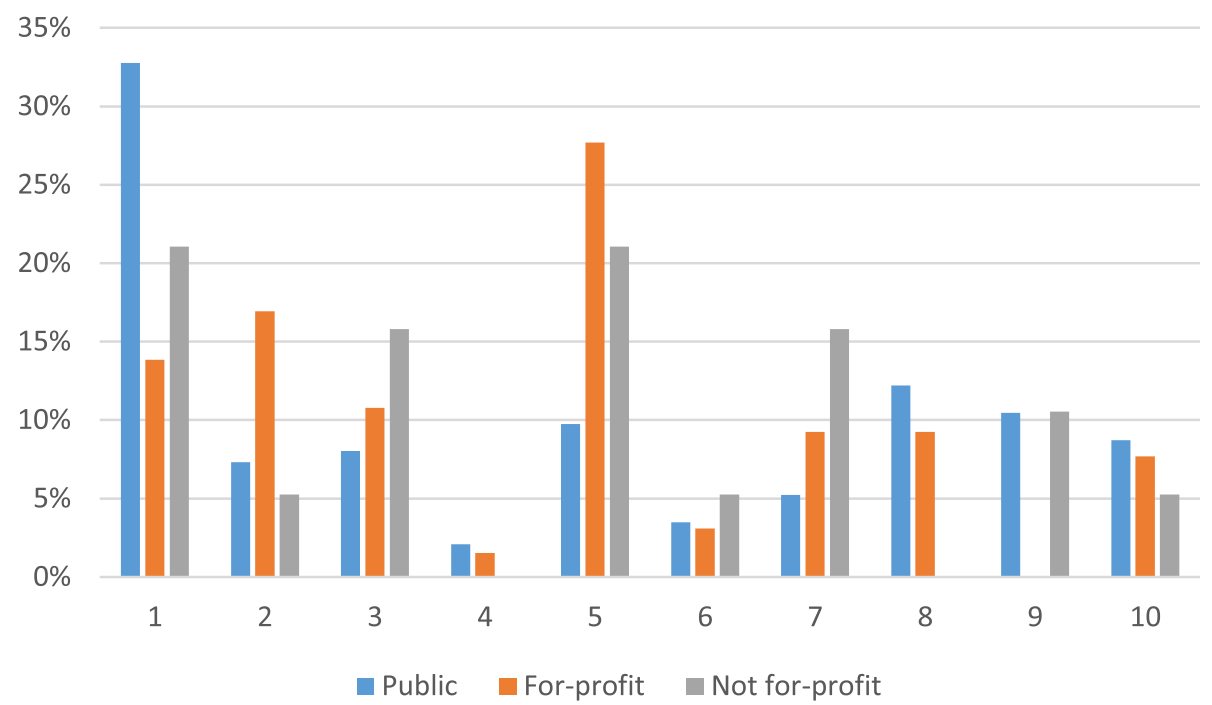

Fig. 1 Relative size of the 10 Robson groups by managing authority $(n=371)$, Ethiopia 2008 and 2016. Group 1: parity 0, no previous CD, singleton, cephalic, $\geq 37$ weeks, spontaneous labor. Group 2: parity 0, no previous CD, singleton, cephalic, $\geq 37$ weeks, induced or CD before labor. Group 3: parity $\geq 1$, no previous CD, singleton, cephalic, $\geq 37$ weeks, spontaneous labor. Group 4: parity $\geq 1$, no previous CD, singleton, cephalic, $\geq 37$ weeks, induced or CD before labor. Group 5: parity $\geq 1$, previous CD, singleton, cephalic, $\geq 37$ weeks, any onset of labor. Group 6: parity 0 , no previous $C D$, singleton, breech, any gestational age, any onset of labor. Group 7: parity $\geq 1$, yes or no previous $C D$, singleton, breech, any gestational age, any onset of labor. Group 8: any parity, yes or no previous CD, multiple fetuses, any fetal lie, any gestational age, any onset of labor. Group 9: any parity, yes or no previous CD, singleton, transverse or oblique lie, any gestational age, any onset of labor. Group 10: any parity, yes or no previous CS, singleton, cephalic, <37 weeks, any onset of labor

the classification scheme is used to inform where changes in clinical management should be made. Our aim in using the Robson classification, however, was to determine the distribution of cases reviewed according to the 10 groups in order to show their relative size, if and how the group size varied across managing authority, and the extent to which the group sizes aligned with other studies.

\section{Statistical analysis}

To produce descriptive statistics (frequencies, percentages, means and medians) we used SPSS version 24. Missing data were usually reported. Since our data sources were censuses and not random samples, nor did they represent some theoretical population, we performed no statistical tests.

\section{Ethical considerations}

This paper utilizes secondary data; permission to use the data was granted by the Ethiopian Public Health Institute and the Family Health Division at the Federal Ministry of Health.

\section{Results}

In 2008, 87 of the 111 hospitals provided cesarean deliveries (66 public sector, 15 private for-profit and 6 private not-for-profit). In 2016, 253 out of 316 hospitals provided cesarean services (188, 52 and 13, respectively).

\section{Cesarean delivery rates}

The national population cesarean rate in 2008 was 0.6 and $2.7 \%$ in 2016 (Table 1). The highly urbanized regions of Harari, Addis Ababa and Dire Dawa exhibited the highest rates in 2016: 17,24 , and $10 \%$, respectively. Elsewhere, rates increased but remained very low.

At the national level, 72 and $74 \%$ of the cesareans were performed in public hospitals in 2008 and 2016, respectively. Half of the cesareans performed in Addis Ababa took place in the private for-profit and private not-forprofit hospitals. The $\mathrm{CD}$ rate in Addis Ababa was likely underestimated in 2008 due to the 12 private hospitals not eligible for the assessment.

The institutional CD rate is the percentage of institutional births delivered by cesarean and is influenced by patient mix and provider practice (Table 2). Patterns of institutional CD rates in 2008 and 2016 were similar: the private for-profit hospitals had the highest rates (46 and $54 \%$, respectively) and the public hospitals had the lowest (15 and 20\%, respectively), while the private not-forprofit hospital rates fell between the other two groups. The percentage increase among public hospitals was 29 , $18 \%$ among private for-profit hospitals, and 7\% among private not-for-profit hospitals.

\section{Hospital readiness to perform cesarean delivery}

Approximately $80 \%$ of hospitals in both time periods provided $\mathrm{CD}$ services in the 3 months prior to the 
Table 1 Absolute numbers of cesarean deliveries (CD), expected births and population-based CD rates, by region and year of assessment

\begin{tabular}{|c|c|c|c|c|c|c|}
\hline Region & Public & Private for-profit & Private not-for-profit & Total CDs & Expected births & Rates \\
\hline \multicolumn{7}{|c|}{ National } \\
\hline 2008 & 12,316 & 2864 & 1965 & 17,145 & $2,638,891$ & $0.6 \%$ \\
\hline 2016 & 58,667 & 13,914 & 6335 & 78,916 & $2,928,303$ & $2.7 \%$ \\
\hline \multicolumn{7}{|l|}{ Tigray } \\
\hline 2008 & 1179 & 2 & 0 & 1181 & 160,929 & $0.7 \%$ \\
\hline 2016 & 5298 & 106 & 0 & 5404 & 163,802 & $3.3 \%$ \\
\hline \multicolumn{7}{|l|}{ Afar } \\
\hline 2008 & 22 & 0 & 0 & 22 & 52,634 & $0.0 \%$ \\
\hline 2016 & 133 & 0 & 96 & 229 & 56,222 & $0.4 \%$ \\
\hline \multicolumn{7}{|l|}{ Amhara } \\
\hline 2008 & 1503 & 28 & 0 & 1531 & 642,084 & $0.2 \%$ \\
\hline 2016 & 9993 & 533 & 437 & 10,963 & 660,518 & $1.7 \%$ \\
\hline \multicolumn{7}{|l|}{ Oromia } \\
\hline 2008 & 2654 & 22 & 1000 & 3676 & $1,013,011$ & $0.4 \%$ \\
\hline 2016 & 16,447 & 1042 & 1751 & 19,240 & $1,099,485$ & $1.7 \%$ \\
\hline \multicolumn{7}{|l|}{ Somali } \\
\hline 2008 & 104 & 8 & 0 & 112 & 165,580 & $0.1 \%$ \\
\hline 2016 & 488 & 39 & 0 & 527 & 178,048 & $0.3 \%$ \\
\hline \multicolumn{7}{|c|}{ Benishangul-Gumuz } \\
\hline 2008 & 166 & 0 & 0 & 166 & 25,023 & $0.7 \%$ \\
\hline 2016 & 700 & 0 & 0 & 700 & 32,913 & $2.1 \%$ \\
\hline \multicolumn{7}{|l|}{ SNNP } \\
\hline 2008 & 1822 & 100 & 536 & 2458 & 561,086 & $0.4 \%$ \\
\hline 2016 & 10,258 & 98 & 2507 & 12,863 & 595,296 & $2.2 \%$ \\
\hline \multicolumn{7}{|c|}{ Gambella } \\
\hline 2008 & 76 & 0 & 0 & 76 & 11,448 & $0.7 \%$ \\
\hline 2016 & 135 & 0 & 0 & 135 & 13,420 & $1.0 \%$ \\
\hline \multicolumn{7}{|l|}{ Harari } \\
\hline 2008 & 648 & 0 & 0 & 648 & 6545 & $9.9 \%$ \\
\hline 2016 & 915 & 381 & 0 & 1296 & 7568 & $17.1 \%$ \\
\hline \multicolumn{7}{|c|}{ Addis Ababa } \\
\hline 2008 & 3918 & 2607 & 429 & 6954 & 97,755 & $7.1 \%$ \\
\hline 2016 & 13,243 & 11,351 & 1544 & 26,138 & 106,625 & $24.5 \%$ \\
\hline \multicolumn{7}{|c|}{ Dire Dawa } \\
\hline 2008 & 224 & 97 & 0 & 321 & 12,239 & $2.6 \%$ \\
\hline 2016 & 1057 & 364 & 0 & 1421 & 14,405 & $9.9 \%$ \\
\hline
\end{tabular}

assessments (Table 3). Among hospitals that had performed CDs, the availability of surgeons, obstetricians and medical doctors declined between 2008 and 2016 when emergency surgical officers (ESOs) began to play a major role, especially in public hospitals. As their name suggests, ESOs are associate clinicians with a three-year master's level of training to conduct common operations such as obstetric surgery, exploratory laparotomy and appendectomy. The cadre was designed to remedy the shortage of obstetrician/gynecologists and surgeons and it recruits from among BSc health officers and BSc nurses. The private for-profit hospitals relied almost entirely on obstetricians, while private not-for-profit hospitals increased their reliance on both obstetricians and 
Table 2 Absolute numbers of cesarean deliveries (CDs) and institutional deliveries and CD rates among hospitals that performed CDs in the last 3 months, by managing authority and year of assessment

\begin{tabular}{|c|c|c|c|c|c|c|}
\hline \multirow{2}{*}{$\begin{array}{l}\text { Managing } \\
\text { Authority }\end{array}$} & \multicolumn{3}{|l|}{2008} & \multicolumn{3}{|l|}{2016} \\
\hline & $\overline{\mathrm{CDs}}$ & Institutional deliveries & Institutional $C D$ rate & $\overline{C D s}$ & Institutional deliveries & Institutional CD rate \\
\hline Public & 12,316 & 80,135 & $15.4 \%$ & 54,983 & 290,150 & $18.9 \%$ \\
\hline Private for-profit & 2864 & 6212 & $46.1 \%$ & 13,810 & 25,384 & $54.4 \%$ \\
\hline Private not-for-profit & 1965 & 7342 & $26.8 \%$ & 6335 & 22,523 & $28.1 \%$ \\
\hline Total & 17,145 & 93,689 & $18.3 \%$ & 75,128 & 338,057 & $22.2 \%$ \\
\hline
\end{tabular}

ESOs. An increase from 95 to $100 \%$ among all hospitals performing CDs reported at least one professional on staff to administer anesthesia.

The availability of drugs and equipment did not change dramatically between the two assessments. In 2016, public hospitals were at some disadvantage compared to private for-profit and private not-for-profit hospitals. For example, in 2016, $85 \%$ of public hospitals had vaporizers compared to 96 to $100 \%$ among the two groups of private hospitals.

Based on the readiness requirements, hospital readiness increased in public hospitals from 70 to $85 \%$ and among private for-profit hospitals from 87 to $97 \%$, but only $67-68 \%$ of private not-for-profit hospitals were staffed and equipped to provide CDs.

We also examined whether hospitals experienced interruptions in electricity and running water. In 2008 virtually all hospitals that regularly performed cesareans had functioning water and electricity in the operation theater or in the hospital itself on the day of the assessment. In 2016 the percentage dropped to closer to $90 \%$ for both electricity and water.

Chart reviews: quality of clinical care and record-keeping In 2008, 95 hospitals provided a total of 275 chart reviews while in 2016, 288 hospitals provided 568 cases. The average age of the women was 26 years in both assessments. However, women whose cesareans were performed in the private for-profit hospitals were on average 28 years of age. In 2016 nearly half (46\%) of the women attending public hospitals were nulliparous, while only $25-28 \%$ of women attending private hospitals were nulliparous.

In both EmONC assessments, more than $75 \%$ of women whose $\mathrm{CD}$ was reviewed had an emergency cesarean (Table 4). As a proportion of reviewed CDs, emergency cesareans were least frequent in the private for-profit settings (47\% in 2008 and 53\% in 2016); emergency cesareans in public and private not-for-profit hospitals ranged from 83 to $85 \%$ in 2008 and to $90-91 \%$ in 2016. Proportionally, about three to four times as many women with a previous cesarean or uterine scar were seen in the two groups of private hospitals compared to public hospitals. This pattern repeated itself in 2016 .
Indications for $\mathrm{CD}$ did not change dramatically although the proportion of $\mathrm{CPD} /$ prolonged labors as an indication increased from 32 to $45 \%$ and breech presentation as an indication decreased from 13 to $3 \%$.

Information related to the quality of the clinical management of CDs is found in Table 5. In 2016, 50\% of the women in the public hospitals whose cases were reviewed received prophylactic uterotonics after the baby was delivered. The percentage was $46 \%$ among women in private for-profit hospitals and $41 \%$ in the private notfor-profit sector. The use of prophylactic antibiotics was higher, with an overall increase from $87 \%$ in 2008 to $94 \%$ in 2016.

Among women whose cesareans were an emergency, defined by having gone into labor, partograph use increased overall from 11 to $35 \%$, occurring almost exclusively in public hospitals (9 to $42 \%$ ).

We analyzed the time from decision to surgery for women with emergency cesareans, despite a high rate of missing information (58\% in 2008 and 66\% in 2016). The median interval in 2008 was 56 min; it increased to $75 \mathrm{~min}$ in 2016. Increases took place across all sectors.

Questions regarding the type of anesthesia administered and the cadre of the surgeon were asked only in 2016. Type of anesthesia varied widely across hospital groups with $81 \%$ of reviewed cases in private not-forprofit hospitals using spinal anesthesia, compared to $49 \%$ in private for-profit hospitals and $60 \%$ among cases in public hospitals. General anesthesia was the second most reported type of anesthesia across all hospitals. In public hospitals, $25 \%$ of women had an obstetrician in attendance, 39\% had a general surgeon and 29\% an emergency surgical officer. In the private for-profit hospitals, $88 \%$ of women were attended by an obstetrician, an additional $7 \%$ had a general surgeon, and no cases were attended by an emergency surgical officer. In the not-for-profit hospitals the percentages were 69\% (obstetrician), 25\% (general surgeon) and 3\% (emergency surgical officer).

Fetal outcomes improved over time with live births increasing from 80 to $94 \%$. The improved fetal outcomes were most evident in private not-for-profit and public hospitals. Maternal deaths among the reviewed cases declined from two in 2008 to one in 2016. 
Table 3 Percent of hospitals that provided cesarean delivery in the last 3 months, and among those, characteristics of readiness, by managing authority and year of assessment

\begin{tabular}{|c|c|c|c|c|c|c|c|c|}
\hline & \multirow{2}{*}{\multicolumn{2}{|c|}{$\begin{array}{l}\text { Total number of } \\
\text { hospitals }\end{array}$}} & \multicolumn{6}{|c|}{ Managing authority } \\
\hline & & & \multicolumn{2}{|l|}{ Public } & \multicolumn{2}{|c|}{ Private for-profit } & \multicolumn{2}{|c|}{ Not-for-profit } \\
\hline & 2008 & 2016 & 2008 & 2016 & 2008 & 2016 & 2008 & 2016 \\
\hline & $n=111$ & $n=316$ & $n=90$ & $n=236$ & $n=15$ & $n=61$ & $n=6$ & $n=19$ \\
\hline \multirow[t]{2}{*}{ Performed CD in last 3 months } & $78 \%$ & $80 \%$ & $73 \%$ & $80 \%$ & $100 \%$ & $85 \%$ & $100 \%$ & $68 \%$ \\
\hline & $n=87$ & $n=253$ & $n=66$ & $n=188$ & $n=15$ & $n=52$ & $n=6$ & $n=13$ \\
\hline \multicolumn{9}{|l|}{ Hospital has HR for surgery ${ }^{a}$} \\
\hline Ob/gyn & $72 \%$ & $50 \%$ & $68 \%$ & $36 \%$ & $100 \%$ & $96 \%$ & $50 \%$ & $77 \%$ \\
\hline General surgeon & $39 \%$ & $9 \%$ & $41 \%$ & $9 \%$ & $27 \%$ & $4 \%$ & $67 \%$ & $46 \%$ \\
\hline Medical doctor & $29 \%$ & $6 \%$ & $35 \%$ & $6 \%$ & $7 \%$ & $2 \%$ & $17 \%$ & $8 \%$ \\
\hline ESOs & na & $63 \%$ & na & $80 \%$ & na & $6 \%$ & na & $39 \%$ \\
\hline Health officer & $9 \%$ & $2 \%$ & $11 \%$ & $2 \%$ & $0 \%$ & $0 \%$ & $17 \%$ & $0 \%$ \\
\hline Midwife & $3 \%$ & $0 \%$ & $3 \%$ & $1 \%$ & $7 \%$ & $0 \%$ & $0 \%$ & $0 \%$ \\
\hline Nurse & $2 \%$ & $0 \%$ & $3 \%$ & $1 \%$ & $0 \%$ & $0 \%$ & $0 \%$ & $0 \%$ \\
\hline At least one person can provide & $98 \%$ & $99 \%$ & $97 \%$ & $100 \%$ & $100 \%$ & $96 \%$ & $100 \%$ & $100 \%$ \\
\hline \multicolumn{9}{|l|}{ Hospital has HR for anesthesia ${ }^{a}$} \\
\hline Anesthesiologist/anesthetist & $91 \%$ & na & $91 \%$ & na & $87 \%$ & na & $100 \%$ & na \\
\hline Anesthesiologist & na & $13 \%$ & na & $10 \%$ & na & $25 \%$ & na & $8 \%$ \\
\hline Anesthetist & na & $95 \%$ & na & $94 \%$ & na & $96 \%$ & na & $100 \%$ \\
\hline Other professional ${ }^{b}$ & $30 \%$ & $3 \%$ & $29 \%$ & $3 \%$ & $33 \%$ & $2 \%$ & $33 \%$ & $8 \%$ \\
\hline At least one person can provide & $95 \%$ & $100 \%$ & $95 \%$ & $100 \%$ & $93 \%$ & $100 \%$ & $100 \%$ & $100 \%$ \\
\hline \multicolumn{9}{|l|}{ Hospital has anesthesia and equipment } \\
\hline Anesthetic vaporizer & $79 \%$ & $88 \%$ & $79 \%$ & $85 \%$ & $87 \%$ & $96 \%$ & $67 \%$ & $100 \%$ \\
\hline Halothane & $84 \%$ & $87 \%$ & $83 \%$ & $86 \%$ & $87 \%$ & $89 \%$ & $83 \%$ & $85 \%$ \\
\hline Ketamine & $94 \%$ & $85 \%$ & $94 \%$ & $84 \%$ & $93 \%$ & $90 \%$ & $100 \%$ & $85 \%$ \\
\hline Lignocaine/lidocaine $4 \%^{c}$ & $95 \%$ & $19 \%$ & $97 \%$ & $18 \%$ & $87 \%$ & $15 \%$ & $100 \%$ & $46 \%$ \\
\hline Bupivacaine & na & $76 \%$ & na & $73 \%$ & na & $83 \%$ & na & $85 \%$ \\
\hline Oxygen cylinder, manometer, flowmeter, tubes, connectors & $94 \%$ & $98 \%$ & $94 \%$ & $98 \%$ & $100 \%$ & $96 \%$ & $83 \%$ & $100 \%$ \\
\hline Operating table & $97 \%$ & $100 \%$ & $96 \%$ & $100 \%$ & $100 \%$ & $100 \%$ & $100 \%$ & $100 \%$ \\
\hline Adjustable shadowless overhead light & $90 \%$ & $94 \%$ & $86 \%$ & $92 \%$ & $100 \%$ & $100 \%$ & $100 \%$ & $100 \%$ \\
\hline Met readiness requirements ${ }^{d}$ & $72 \%$ & $86 \%$ & $70 \%$ & $85 \%$ & $87 \%$ & $97 \%$ & $67 \%$ & $68 \%$ \\
\hline OT with electricity at visit ${ }^{\mathrm{e}}$ & $99 \%$ & $92 \%$ & $100 \%$ & $94 \%$ & $100 \%$ & $94 \%$ & $83 \%$ & $100 \%$ \\
\hline OT with water at visit & $99 \%$ & $89 \%$ & $99 \%$ & $86 \%$ & $100 \%$ & $94 \%$ & $100 \%$ & $100 \%$ \\
\hline
\end{tabular}

na not applicable/not included in 2008, CD cesarean delivery, ob/gyn obstetrician/gynecologist, HR human resources, OT operating theater, ESOs emergency surgical officers

${ }^{a}$ The 2016 human resource module was worded differently from 2008 and additional questions were used

b Ob/gyns, pediatricians, medical doctors, general surgeons, ESOs, health officers and nurses

c In 2008, the question asked about lidocaine 1 or $2 \%$

${ }^{d}$ Defined as [at least 1 professional to conduct operation +1 for anesthesia] AND [EITHER an anesthesia machine + halothane or ketamine OR regional anesthesia (lignocaine/lidocaine $4 \%$ or bupivacaine)] AND [an oxygen cylinder with manometer, flowmeter, tubes and connectors + an operating table + overhead light]

e In 2008, the question referred to functioning power in the facility on day of interview, not the OT

\section{Robson classification}

Figure 1 shows the relative contribution of each Robson group to all CDs reviewed by managing authority. In public hospitals, Robson group 1 accounted for 33\% of the cesareans reviewed, followed by group 8 (12\%). In the private for-profit hospitals, group 5 dominated (28\%), followed by group 2 (17\%). This aligns with the findings on indications (Table 4), in which "previous cesarean" was the second most frequent indication in private for-profit hospitals. Forty-two percent of the reviewed cesareans from the private not-for-profit hospitals were women belonging equally to groups 1 and 5 . As stated earlier, about a third of the cases suffered missing information and could not be grouped. 
Table 4 Percent distribution of cesarean deliveries reviewed according to indication, by managing authority and year of assessment

\begin{tabular}{|c|c|c|c|c|c|c|c|c|}
\hline \multirow{4}{*}{$\begin{array}{l}\text { Type and indication for } \\
\text { cesareans }\end{array}$} & \multirow{2}{*}{\multicolumn{2}{|c|}{$\begin{array}{l}\text { All cesareans } \\
\text { reviewed }\end{array}$}} & \multicolumn{6}{|c|}{ Managing authority } \\
\hline & & & \multicolumn{2}{|c|}{ Public } & \multicolumn{2}{|c|}{ Private for-profit } & \multicolumn{2}{|c|}{ Not-for-profit } \\
\hline & 2008 & 2016 & 2008 & 2016 & 2008 & 2016 & 2008 & 2016 \\
\hline & $n=275$ & $n=566$ & $n=209$ & $n=409$ & $n=45$ & $n=125$ & $n=21$ & $n=32$ \\
\hline \multicolumn{9}{|l|}{ Type of cesarean } \\
\hline Emergency & $77 \%$ & $82 \%$ & $83 \%$ & $90 \%$ & $47 \%$ & $53 \%$ & $85 \%$ & $91 \%$ \\
\hline Elective & $21 \%$ & $12 \%$ & $15 \%$ & $6 \%$ & $51 \%$ & $32 \%$ & $15 \%$ & $6 \%$ \\
\hline No information & $2 \%$ & $6 \%$ & $2 \%$ & $4 \%$ & $2 \%$ & $15 \%$ & $0 \%$ & $3 \%$ \\
\hline \multicolumn{9}{|l|}{ Maternal indications } \\
\hline CPD/prolonged labor ${ }^{a}$ & $34 \%$ & $45 \%$ & $36 \%$ & $50 \%$ & $27 \%$ & $28 \%$ & $26 \%$ & $40 \%$ \\
\hline Previous cesarean & $11 \%$ & $13 \%$ & $7 \%$ & $8 \%$ & $27 \%$ & $26 \%$ & $21 \%$ & $22 \%$ \\
\hline Placenta praevia/abruption & $7 \%$ & $6 \%$ & $7 \%$ & $7 \%$ & $2 \%$ & $4 \%$ & $16 \%$ & $3 \%$ \\
\hline Severe PE/E & $6 \%$ & $4 \%$ & $7 \%$ & $4 \%$ & $4 \%$ & $2 \%$ & $0 \%$ & $6 \%$ \\
\hline Other maternal indications ${ }^{b}$ & $9 \%$ & $5 \%$ & $10 \%$ & $3 \%$ & $8 \%$ & $11 \%$ & $0 \%$ & $5 \%$ \\
\hline \multicolumn{9}{|l|}{ Fetal indications } \\
\hline Fetal distress ${ }^{c}$ & $15 \%$ & $13 \%$ & $13 \%$ & $14 \%$ & $20 \%$ & $11 \%$ & $21 \%$ & $12 \%$ \\
\hline Breech & $14 \%$ & $3 \%$ & $17 \%$ & $4 \%$ & $2 \%$ & $2 \%$ & $11 \%$ & $3 \%$ \\
\hline Cord prolapse & $2 \%$ & $2 \%$ & $3 \%$ & $2 \%$ & $0 \%$ & $2 \%$ & $0 \%$ & $3 \%$ \\
\hline Multiple gestation & $0 \%$ & $3 \%$ & $0 \%$ & $3 \%$ & $0 \%$ & $2 \%$ & $0 \%$ & $0 \%$ \\
\hline Other fetal indications ${ }^{d}$ & $2 \%$ & $3 \%$ & $1 \%$ & $2 \%$ & $8 \%$ & $4 \%$ & $5 \%$ & $6 \%$ \\
\hline No information & $0 \%$ & $4 \%$ & $0 \%$ & $3 \%$ & $2 \%$ & $7 \%$ & $0 \%$ & $0 \%$ \\
\hline
\end{tabular}

\section{Discussion}

Nationally, Ethiopia exhibits a large unmet need for cesarean delivery. When disaggregated by region, CD rates ranged from $24 \%$ in Addis Ababa to under $1 \%$ in pastoralist regions. Rates were highest in highly urbanized regions where private for-profit hospitals contributed between 25 and $50 \%$ of all cesareans. Although public hospitals provided the bulk of obstetric services, by 2016 more than half (54\%) of all deliveries in private for-profit hospitals were cesareans. Private for-profit hospitals exhibited the highest elective $\mathrm{CD}$ rate. Hospital readiness to perform a cesarean showed signs of improvement, and a larger proportion of hospitals overall met minimum staffing and equipment requirements in 2016 than in 2008. Private for-profit hospitals demonstrated the lowest partograph use (6\%) while partograph use increased from 9 to $42 \%$ in public hospitals and declined among private not-for-profit hospitals from 47 to $27 \%$. In 2016, $40 \%$ of CD reviews from public hospitals were among low-risk nulliparous women (Robson groups $1 \& 2$ ) and $45 \%$ of chart reviews at private forprofit hospitals consisted of Robson groups 2 and 5.

Despite the tripling of the overall number of hospitals between 2008 and 2016, both assessments indicated that about four out of five hospitals provided CD services, perhaps indicating an opportunity to increase access with minimal investment. The lack of universal water and electricity in hospitals in 2016 might have been a result of the rapid expansion in infrastructure. One enabling factor for improvements in hospital readiness was likely the establishment in 2009 of the emergency surgical officer [21]. Four out of five public hospitals with CD services employed ESOs. A large push to prepare anesthetists also took place during this time period [21].

Chart reviews revealed how patient profiles and provider practices varied by managing authority. The private for-profit and private not-for-profit hospitals disproportionately attracted women with a previous CD and nonemergency cases. The chart reviews also pointed to mixed results regarding the practice of evidence-based interventions. The use of partographs to monitor labor more than tripled in public hospitals while the partograph was hardly used or declined elsewhere. Uterotonics administered after the baby was delivered and prophylactic antibiotic use were also more evident in public hospitals than elsewhere. These three interventions can help prevent serious complications and all women who undergo a cesarean delivery should receive 
Table 5 Percent or percent distribution of cesarean deliveries reviewed according to administration of prophylactic uterotonics and antibiotics, use of partograph, time interval between decision and operation, type of anesthesia and practitioner and fetal outcomes, by managing authority and year of assessment

\begin{tabular}{|c|c|c|c|c|c|c|c|c|}
\hline & \multirow{2}{*}{\multicolumn{2}{|c|}{$\begin{array}{l}\text { All cesareans } \\
\text { reviewed }\end{array}$}} & \multicolumn{6}{|c|}{ Managing authority } \\
\hline & & & \multicolumn{2}{|l|}{ Public } & \multicolumn{2}{|c|}{ Private-for-profit } & \multicolumn{2}{|c|}{ Not-for-profit } \\
\hline & 2008 & 2016 & 2008 & 2016 & 2008 & 2016 & 2008 & 2016 \\
\hline & $n=275$ & $n=568$ & $n=209$ & $n=409$ & $n=45$ & $n=127$ & $n=21$ & $n=32$ \\
\hline Prophylactic uterotonics administered after baby delivered & na & $50 \%$ & na & $52 \%$ & na & $46 \%$ & na & $41 \%$ \\
\hline Prophylactic antibiotics administered ${ }^{a}$ & $87 \%$ & $94 \%$ & $86 \%$ & $94 \%$ & $93 \%$ & $91 \%$ & $85 \%$ & $94 \%$ \\
\hline Partograph use among women with non-elective cesareans & $n=211$ & $n=499$ & $n=172$ & $n=383$ & $n=22$ & $n=86$ & $n=17$ & $n=30$ \\
\hline Partograph used & $11 \%$ & $35 \%$ & $9 \%$ & $42 \%$ & $0 \%$ & $6 \%$ & $47 \%$ & $27 \%$ \\
\hline Partograph not used & $88 \%$ & $55 \%$ & $90 \%$ & $49 \%$ & $100 \%$ & $78 \%$ & $53 \%$ & $60 \%$ \\
\hline Planned elective went into labor & na & $6 \%$ & na & $5 \%$ & na & $9 \%$ & na & $7 \%$ \\
\hline No information & $1 \%$ & $4 \%$ & $1 \%$ & $4 \%$ & $0 \%$ & $7 \%$ & $0 \%$ & $6 \%$ \\
\hline Time interval between decision and operation ${ }^{b}$ & $n=82$ & $n=148$ & $n=64$ & $n=130$ & $n=11$ & $n=9$ & $n=7$ & $n=9$ \\
\hline Mean (minutes) & 310 & 210 & 277 & 202 & 441 & 308 & 289 & 232 \\
\hline Median (minutes) & 56 & 76 & 60 & 80 & 45 & 60 & 30 & 45 \\
\hline \multicolumn{9}{|l|}{ Type of anesthesia used } \\
\hline Spinal/epidural (1 case) & na & $59 \%$ & na & $60 \%$ & na & $49 \%$ & na & $81 \%$ \\
\hline General & na & $28 \%$ & na & $24 \%$ & na & $36 \%$ & na & $9 \%$ \\
\hline Ketamine & na & $4 \%$ & na & $5 \%$ & na & $2 \%$ & na & $6 \%$ \\
\hline No information & na & $9 \%$ & na & $8 \%$ & na & $13 \%$ & na & $3 \%$ \\
\hline \multicolumn{9}{|l|}{ Type of surgeon } \\
\hline Ob/gyn & na & $41 \%$ & na & $25 \%$ & na & $88 \%$ & na & $69 \%$ \\
\hline General surgeon & na & $31 \%$ & na & $38 \%$ & na & $7 \%$ & na & $25 \%$ \\
\hline ESO & na & $21 \%$ & na & $29 \%$ & na & $0 \%$ & na & $3 \%$ \\
\hline Health officer & na & $3 \%$ & na & $4 \%$ & na & $0 \%$ & na & $0 \%$ \\
\hline General practitioner & na & $1 \%$ & na & $2 \%$ & na & $0 \%$ & na & $3 \%$ \\
\hline MSC midwife & na & $1 \%$ & na & $1 \%$ & na & $0 \%$ & na & $0 \%$ \\
\hline No information & na & $2 \%$ & na & $1 \%$ & na & $5 \%$ & na & $0 \%$ \\
\hline Fetal Outcomes & $n=275$ & $n=566$ & $n=209$ & $n=409$ & $n=45$ & $n=125$ & $n=21$ & $n=32$ \\
\hline Live birth & $79 \%$ & $95 \%$ & $78 \%$ & $94 \%$ & $93 \%$ & $93 \%$ & $71 \%$ & $91 \%$ \\
\hline Stillbirth & $9 \%$ & $2 \%$ & $11 \%$ & $3 \%$ & $2 \%$ & $2 \%$ & $5 \%$ & $3 \%$ \\
\hline Neonatal death & $5 \%$ & $<1 \%$ & $5 \%$ & $0 \%$ & $4 \%$ & $0 \%$ & $5 \%$ & $0 \%$ \\
\hline Live birth + death & $2 \%$ & $<1 \%$ & $2 \%$ & $0 \%$ & $0 \%$ & $0 \%$ & $0 \%$ & $0 \%$ \\
\hline No information & $5 \%$ & $3 \%$ & $5 \%$ & $2 \%$ & $0 \%$ & $6 \%$ & $19 \%$ & $6 \%$ \\
\hline
\end{tabular}

na not applicable/not included in 2008, ESO emergency surgical officer, MSC BSc midwife with surgical training

a In 2008, the timing of antibiotics was not specified. In 2016, timing reflects antibiotics given either pre- or post-operatively. If no documentation of antibiotics was recorded, we assumed the woman did not receive them

${ }^{\mathrm{b}}$ Asked of emergency cesarean deliveries only

them. Thus, it is encouraging that contrary to other experiences [25], public hospitals performed as well if not better than private hospitals.

The inclusion of the Robson classification parameters in 2016 enabled us to see clearly the perpetuation of "once a cesarean, always a cesarean," especially among the women who delivered in private for-profit and private not-for-profit hospitals given the contribution of group 5 to these two groups of hospitals.
Typically, groups $1,2,3,4$ and 5 contribute heavily to the overall $\mathrm{CD}$ rate, while groups $6-10$ account for a smaller proportion of all cesareans. According to a WHO multi-country study from 21 countries and 287 hospitals, groups $6-10$ accounted for only $20 \%$ of the cesareans [26]. In our case, groups 6-10 accounted for $38 \%$ of the cases. This might reflect Ethiopia's overall low cesarean rate and that higher risk women contributed more to the pool of cesareans than in the WHO 
multicenter study. As the overall cesarean rate in Ethiopia increases, the contribution of groups 6-10 relative to other groups may decline. Nevertheless, it is worrisome that $40 \%$ of the chart reviews at public hospitals were among low risk nulliparous women. One of the goals of this classification system is to reduce cesareans among groups 1 and 2, who are known to be vulnerable to unnecessary CDs, and who are often the biggest group as we observed in this study [26]. Overuse of CD among these groups sets up a domino effect that contributes to repeated cesareans.

The two extremes - widespread underutilization of life-saving surgical care and the overutilization of a costly procedure not without risk - is an opportunity for Ethiopia, and other low and middle income settings faced with similar dual challenges, to improve availability and access to quality $\mathrm{CD}$ care and general coverage by elevating rates where needed, while learning from high income regions' mistakes of overusing cesarean delivery.

\section{Strengths and limitations}

A strength of this paper is the richness of its data sources: two national health facility censuses that enabled comparisons between public and private managing authorities. Analyses drew on data from interviews with health workers, observation of infrastructure, 12 months of service statistics, and individual level data from women who had undergone a cesarean, resulting in a multifaceted overview of how rates, hospital readiness and quality of clinical management of cesarean delivery changed as well as suggesting some steps going forward. Results regarding the specifics of hospital readiness are highly generalizable since all or nearly all hospitals were included in the assessments.

We recognize that observation generally produces more accurate results than reporting, especially if recall is required. Hospital readiness depended heavily on responses from staff rather than observation, for example, whether an oxygen cylinder was both available and functional. Furthermore, readiness results will change as do the requirements, and we encourage strengthening the definition of readiness.

Data quality of the primary sources - admission, operating theater and discharge logbooks - is a wellrecognized limitation when working with health facility data. We are not clear why an increase in missing information occurred between the two assessments, especially among the case reviews. The inability to classify a third of the cesareans reviews into one of the 10 Robson groups points to omissions in record-keeping, even though the six parameters used to group women are considered standard data items. The group that suffered the least amount of missing information (20 cases) was group 8 , defined only by singleton or multiple gestation.
Group 5 suffered the most from missing information: 132 of 568 cases lacked at least one of the five variables that defined group 5, with "previous cesarean" the most frequently missing.

The chart reviews were systematically selected but were technically a convenience sample, and do not represent all cesareans, especially those conducted in the private for-profit hospitals where missing data tended to be the highest. Similar studies have struggled with the use of non-randomly selected chart reviews but also recognized their value when presenting an overview of a single service delivery intervention [27].

Some variables were only available in 2016 and the rewording of some questions affected our ability to make precise comparisons for other variables, but periodic surveys often undergo modifications in their data collection instruments, which are intended to enhance the data quality over time.

\section{Conclusions}

During the 8-year interval between assessments, the government tripled the number of hospitals, raised the $C D$ delivery rate in underserved regions, and improved both the readiness to perform obstetric operations and the quality of clinical care. The data also point to dangerously low $\mathrm{CD}$ rates in underserved rural areas. More equitable access to cesarean services can be achieved through strengthened referral systems, hospital maternity waiting homes and the continued expansion of facilities that fill geospatial gaps [28, 29]. Meanwhile, high institutional $\mathrm{CD}$ rates in the private sector, especially private for-profit hospitals, suggest that not all cesareans may be medically indicated. Federal normative bodies as well as professional societies should investigate local conditions to identify what is driving the demand: financial incentives on the supply side, professional inexperience with non-routine vaginal births, or other forces. The use of the Robson classification would be a useful tool for future quality improvement efforts - to ensure that the right women are receiving this procedure while others are protected from unnecessary procedures.

\section{Supplementary Information}

The online version contains supplementary material available at https://doi. org/10.1186/s12884-021-04008-9.

Additional file 1: Module 1. Identification of facility and infrastructure.

Additional file 2: Module 2. Human resources.

Additional file 3: Module 3. Essential Drugs, Equipment, and Supplies. Additional file 4: Module 4. Facility Case Summary.

Additional file 5: Module 5. EmOC and EmNeC Signal Functions and Other Essential Services.

Additional file 6: Module 8. Cesarean Delivery Review. 


\section{Acknowledgements}

We would like to thank EPHI and the Ministry of Health for their sharing of the datasets. In addition, we thank the Bill and Melinda Gates Foundation and AMDD for their support of the paper writing workshop.

\section{Authors' contributions}

$M G B$ took the lead on conceptualizing the paper and writing the first draft. TGZ, AH, ALR and PB reviewed and revised. TGZ and PB did the statistical analyses. The authors read and approved the final manuscript.

\section{Funding}

The Bill and Melinda Gates Foundation provided initial support to all of the authors. However, the Foundation played no role in the design of the study, the data collection, analysis or interpretation of the data. They also had no influence in the writing process.

\section{Availability of data and materials}

The datasets generated and analyzed for this study are available from the Ethiopian Public Health Institute Director on reasonable request.

\section{Declarations}

\section{Ethics approval and consent to participate}

This paper is the result of secondary data analysis of two national assessments. We received permission to access and use the data from the Ethiopian Public Health Institute and the Family Health Division of the Federal Ministry of Health.

\section{Consent for publication}

Not applicable.

\section{Competing interests}

None of the authors has any competing interests.

\section{Author details}

${ }^{1}$ Ethiopian Public Health Institute, Addis Ababa, Ethiopia. ${ }^{2}$ World Health Organization, Lusaka, Zambia. ${ }^{3}$ Centre for International Health, Department of Global Public Health and Primary Care, University of Bergen, Bergen, Norway. ${ }^{4}$ Consultant with Averting Maternal Death and Disability Program, Mailman School of Public Health, Columbia University, New York, USA.

Received: 24 September 2020 Accepted: 19 July 2021

Published online: 19 August 2021

\section{References}

1. Miller S, Abalos E, Chamillard M, Ciapponi A, Colaci D, Comande D, et al. Beyond too little, too late and too much, too soon: a pathway towards evidence-based, respectful maternity care worldwide. Lancet. 2016; 388(10056):2176-92. https://doi.org/10.1016/S0140-6736(16)31472-6.

2. World Health Organization. Appropriate Technology for Birth. Lancet. 1985; 326(8452):436-7.

3. Ye J, Betrán AP, Guerrero Vela M, Souza JP, Zhang J. Searching for the optimal rate of medically necessary cesarean delivery. Birth. 2014;41(3):23744. https://doi.org/10.1111/birt.12104

4. World Health Organization Human Reproduction Programme A. WHO statement on caesarean section rates. Reprod Health Matters. 2015;23(45): 149-50

5. Rijken MJ, Meguid T, van den Akker T, van Roosmalen J, Stekelenburg J. Dutch working Party for International Safe Motherhood, reproductive health: global surgery and the dilemma for obstetricians. Lancet. 2015; 386(10007):1941-2. https://doi.org/10.1016/S0140-6736(15)00828-4.

6. Wright J, Ayenachew F, Ballard KD. The changing face of obstetric fistula surgery in Ethiopia. Int J Women's Health. 2016;8:243-8. https://doi.org/1 $0.2147 /$ IJWH.S106645.

7. Belizán JM, Althabe F, Cafferata ML. Health consequences of the increasing caesarean section rates. Epidemiology. 2007;18(4):485-6. https://doi.org/10.1 097/EDE.0b013e318068646a.

8. Boerma T, Melesse D, Barros AJ, Barros F, Juan L, Moller AB, et al. Global epidemiology of use of and disparities in caesarean sections. Lancet. 2018; 392:8.
9. Meara JG, Greenberg SL. The lancet commission on global surgery global surgery 2030: evidence and solutions for achieving health, welfare and economic development. Surgery. 2015;157(5):834-5. https://doi.org/10.1016/ j.surg.2015.02.009.

10. Biccard BM, Madiba TE, Kluyts HL, Munlemvo DM, Madzimbamuto FD, Basenero A, et al. Perioperative patient outcomes in the African surgical outcomes study: a 7-day prospective observational cohort study. Lancet. 2018;391(10130):1589-98. https://doi.org/10.1016/S0140-6736(18)30001-1.

11. Central Statistical Agency [Ethiopia], ICF. Ethiopia Demographic and Health Survey 2016. Addis Ababa, Ethiopia and Rockville: CSA and ICF; 2016.

12. Gebremedhin S. Trend and socio-demographic differentials of caesarean section rate in Addis Ababa, Ethiopia: analysis based on Ethiopia demographic and health surveys data. Reprod Health. 2014;11(1):14. https:// doi.org/10.1186/1742-4755-11-14

13. Cavallaro FL, Cresswell JA, Franca GV, Victora CG, Barros AJ, Ronsmans C. Trends in caesarean delivery by country and wealth quintile: cross-sectional surveys in southern Asia and sub-Saharan Africa. Bull World Health Organ. 2013;91(12):914-922D. https://doi.org/10.2471/BLT.13.117598.

14. Ethiopian Federal Ministry of Health. Health Sector Transformation Plan (2015/16-2019/20), vol. 20. Addis Ababa; 2015

15. Fesseha N, Getachew A, Hiluf M, Gebrehiwot Y, Bailey P. A national review of cesarean delivery in Ethiopia. Int J Gynecol Obstet. 2011;115(1):106-11. https://doi.org/10.1016/j.ijgo.2011.07.011.

16. Federal Ministry of Health of Ethiopia, UNICEF, UNFPA, WHO, AMDD. National baseline assessment for emergency obstetric \& newborn care Ethiopia 2008. Addis Ababa; 2009. p. 245.

17. Ethiopian Public Health Institute, Federal Ministry of Health, AMDD. Ethiopian Emergency Obstetric and Newborn Care (EmONC) Assessment 2016 Final Report. Addis Ababa; 2017. p. 456.

18. Averting Maternal Death and Disability (AMDD) Toolkit. https://www.mailma n.columbia.edu/research/averting-maternal-death-and-disability-amdd/ toolkit. Accessed 6 Feb 2021

19. Keyes EB, Haile-Mariam A, Tesfaye NB, Wasihun GA, Pearson L, Abdullah M, et al. Ethiopia's assessment of emergency obstetric and newborn care: setting the gold standard for national facility-based assessments. Int J Gynecol Obstet 2011;115(1):94-100. https://doi.org/10.1016/.ijgo.2011.07.009.

20. Ethiopian Federal Ministry of Health. Health Sector Development Program, vol. 4. Addis Ababa: Federal Ministry of Health; 2010. 2010/11-2014/15.

21. Ethiopia Ministry of Health, PMNCH, World Health Organization, World Bank, AHPSR. Success Factors for Women's and Children's Health. Ethiopia; 2015. p. 28.

22. Federal Ministry of Health of Ethioipa. Health and Health Related Indicators 2012-2013. Addis Ababa; 2014.

23. WHO, UNFPA, UNICEF, AMDD. Monitoring emergency obstetric care: a handbook, vol. 152. Geneva: World Health Organization; 2009.

24. Robson MS. Classification of caesarean sections. Fetal Maternal Med Rev. 2001;12(1):23-39. https://doi.org/10.1017/S0965539501000122.

25. Kruk ME, Leslie HH, Verguet S, Mbaruku GM, Adanu RM, Langer A. Quality of basic maternal care functions in health facilities of five African countries: an analysis of national health system surveys. Lancet Glob Health. 2016;4(11): e845-55. https://doi.org/10.1016/S2214-109X(16)30180-2.

26. Betrán AP, Gulmezoglu AM, Robson M, Merialdi M, Souza JP, Wojdyla D, et al. WHO global survey on maternal and perinatal health in Latin America: classifying caesarean sections. Reprod Health. 2009;6(1):18. https://doi.org/1 0.1186/1742-4755-6-18

27. Kim YM, Tappis H, Zainullah P, Ansari N, Evans C, Bartlett L, et al. Quality of caesarean delivery services and documentation in first-line referral facilities in Afghanistan: a chart review. BMC Pregnancy Childbirth. 2012;12(1):14. https://doi.org/10.1186/1471-2393-12-14.

28. Tiruneh GT, Getu YN, Abdukie MA, Eba GG, Keyes E, Bailey PE. Distribution of maternity waiting homes and their correlation with perinatal mortality and direct obstetric complication rates in Ethiopia. BMC Pregnancy Childbirth. 2019;19(1):214. https://doi.org/10.1186/s12884-019-2356-x.

29. Bailey PE, Keyes EB, Parker C, Abdullah M, Kebede H, Freedman L. Using a GIS to model interventions to strengthen the emergency referral system for maternal and newborn health in Ethiopia. Int J Gynecol Obstet. 2011;115(3): 300-9. https://doi.org/10.1016/j.ijgo.2011.09.004.

\section{Publisher's Note}

Springer Nature remains neutral with regard to jurisdictional claims in published maps and institutional affiliations. 